\title{
LOJAS DE CONVENIÊNCIA E MARKETING DIGITAL COMO AGREGAÇÃO DE VALOR EM UM POSTO DE COMBUSTÍVEL: O caso do Comércio de Combustíveis Lara LTDA
}

\author{
Leandro SCHNEIDER ${ }^{1}$ \\ Lurdes Marlene Seide FROEMMING ${ }^{2}$ \\ Daniel Knebel BAGGIO ${ }^{3}$ \\ Bruno KONZEN ${ }^{4}$ \\ Telmo Rudi FRANTZ 5
}

\begin{abstract}
${ }^{1}$ Mestrando em Desenvolvimento - Universidade Regional do Noroeste do Estado Rio Grande do Sul; leandro.mkt895@gmail.com

${ }^{2}$ Doutora e Professora - Universidade Regional do Noroeste do Estado do Rio Grande do Sul; lurdesf@unijui.edu.br

${ }^{3}$ Doutor e Professor - Universidade Regional do Noroeste do Estado do Rio Grande do Sul; baggiod@ unijui.edu.br

${ }^{4}$ Especialista Finanças e Mercado de Capitais - Universidade Regional do Noroeste do Estado Rio Grande do Sul; bruno_konzen@brturbo.com.br

${ }^{5}$ Doutor e Professor - Universidade Regional do Noroeste do Estado do Rio Grande do Sul; telmo.frantz1@unijui.edu.br
\end{abstract}

Recebido em: 02/11/2016 - Aprovado em: 25/10/2017 - Disponibilizado em: 30/12/2017

\begin{abstract}
RESUMO
O presente artigo tem como objetivo conhecer o perfil dos clientes do Posto e Conveniência Lara, bem como analisar sua percepção da agregação de valor na utilização do marketing digital e implantação de uma loja de conveniência em um posto de combustíveis. Trata-se de uma pesquisa social aplicada de caráter descritivo, utilizando-se de uma investigação de levantamento e pesquisa bibliográfica. A amostra se constituiu de cento e cinquenta pessoas escolhidas de forma não probabilística nas dependências da organização em estudo e, o instrumento utilizado foi um questionário. Os resultados obtidos expressam que a organização tem satisfeito seus clientes em quesitos como qualidade, limpeza e conveniência, porém tem deixado a desejar nas questões de atendimento e diversidade de produtos, sendo o marketing digital um impulsionador a escolha da organização pelos clientes, bem como uma ferramenta de fortalecimento da marca da organização, tornando assim a mesma mais conhecida e diferenciada entre os concorrentes.
\end{abstract}

Palavras chave: Conveniência. Valor. Posto de Combustíveis. Marketing. Digital.

\begin{abstract}
This article has the objective to know the profile of the customers of the Posto e Conveniência Lara as well as analyze their perception of value addition in the use of digital marketing and deployment of a convenience store in a gas station. This is a search of character social aplied descriptive, using a research survey and literature search. The sample consisted of one hundred and fifty people selected a non probabilistic way at the organization of the study, and the instrument used was a questionnaire. The results obtained were that the organization has satisfied their customers on issues such as quality, cleanliness and convenience, but it has left to desire in the matters of service and product diversity issues, being the digital marketing a booster the choice of organization by the customers, as well tool of strengthening the brand of the organization, thus making it more known and differentiated from competitors.
\end{abstract}

Keywords: Convenience. Value. Gas Station. Digital Marketing. 


\section{INTRODUÇÃO}

Em uma era onde a informação encontra-se disponível para todos, a busca por uma diferenciação frente à concorrência se torna cada vez mais complexa, uma vez que nada é novidade por muito tempo quando falamos em estratégias empresariais e busca por diferenciais competitivos.

Desta forma a busca por um diferencial para os clientes parte com base na opinião dos mesmos, que deve ser medida e analisados frequentemente no intuito de novos resultados dentro da organização, pois o diferencial se encontra em ser mais eficaz na resolução das necessidades de seus clientes do que a concorrência, o satisfazendo e o fidelizando assim à organização.

O presente artigo buscou demonstrar a importância de uma pesquisa frente aos clientes da organização, na busca por novas ideias para melhor satisfaze-los e averiguar o que vem sendo feito de forma eficaz neste sentido, bem como a analise de valor percebida pelos clientes na implantação de uma conveniência junto ao Posto Lara como alternativa também na busca por um diferencial, fornecendo subsídios para possíveis tomadas de decisão futuras com base nos dados coletados.

Por fim, faz-se uma análise de como as novas tecnologias, por meio do marketing digital são capazes de satisfazer e fidelizar o cliente, bem como são resultantes de um diferencial competitivo de relacionamento com o consumidor lhe proporcionando uma percepção de valor para com a organização.

\section{LOJAS DE CONVENIÊNCIA}

Segundo Levy e Weitz (2000) as lojas de conveniência permitem aos consumidores fazerem compras rapidamente, sem ter que pesquisar em uma loja grande e esperar em longas filas de controle de saída. Mais da metade dos itens comprados são consumidos em até 30 minutos após a compra. Devido ao seu tamanho pequeno e alta rotatividade, as lojas de conveniência normalmente recebem entregas de 3 a 4 dias por semana.

Segunda Ferreira (2008) conveniência seria a qualidade do que é conveniente, ou seja, o que é cômodo para as pessoas, e também desejado, conveniência em atividade comercial, seria uma organização responsável por providenciar mercadorias e serviços desejados pelos consumidores, possibilitando rapidez, facilidade e englobe como no caso dos postos de combustível, vários fatores de necessidade dos clientes em um modelo só, como um local para abastecer os veículos, com facilidade de estacionamento, segurança e que comercialize também produtos de sua necessidade diária.

Por se tratarem de lojas com um sortimento de mercadorias limitado e uma estrutura física de pequeno porte, as lojas de conveniência são comparadas, e por vezes chamadas até de as versões modernas dos antigos armazéns de vizinhança ou 
mercearias, que possuíam também uma gama de produtos na busca por atender todas as necessidades dos clientes.

\section{VALOR PARA O CLIENTE}

Para qualquer organização que opere em qualquer lugar do mundo, a essência de marketing é superar os concorrentes na tarefa de criar valor visível para os consumidores. O valor se caracteriza como um conjunto de benefícios e preço, onde uma vez que melhorados os benefícios associados ao produto, distribuição ou comunicações, haverá um aumento também do valor. Este pode ser aumentado também através diminuição de preço inerente ao mesmo.

Para Gordon (2002), o vínculo de valor ocorre quando os clientes repetidamente obtêm o valor que procuram de seus fornecedores e têm todos os motivos para acreditar que continuarão a receber este valor durante um longo período. Seja ela da forma que for, esta criação de valor por parte do cliente acaba por deixa-lo fiel a organização.

Para que perceba vantagem na parceria às empresas devem criar valor sob a visão do cliente. Na concepção de Cobra (2002) para se saber o que representa valor para o cliente deve-se pesquisar junto ao mesmo. Identificando assim suas preferências e quais as ações a serem tomadas frente as descobertas feitas.

\section{MARKETING DIGITAL}

Segundo Limeira (2003) com a evolução da tecnologia da informação e comunicação, especialmente a internet, o marketing evoluiu para o chamado marketing eletrônico e-marketing ou marketing digital, conceito que expressa o conjunto de ações de marketing intermediadas por canais eletrônicos como a internet em que o cliente controla a quantidade e o tipo de informação recebida.

De acordo com Cintra (2010) O marketing digital pode colocar a empresa no seleto rol de negócios que têm na evolução da informação o maior diferencial competitivo. Transformando o relacionamento e a informação em mais um atrativo e forma de fidelizar os clientes a organização.

\section{METODOLOGIA}

Segundo Gil (2002) toda e qualquer classificação se faz mediante algum critério. Com relação às pesquisas, é usual a classificação com base em seus objetivos gerais. Desta forma, tratar-se de uma pesquisa de caráter descritivo uma vez que o objetivo principal é a descrição de características de determinada população, juntamente com um fenômeno a ser tratado em relação a satisfação e o estabelecimento de relações entre as variáveis.

Os meios de investigação utilizados foram o de levantamento, uma vez que a pesquisa se caracteriza pela interrogação 
direta das pessoas cujo comportamento se deseja conhecer, de forma a identificar através destes dados possíveis mudanças dentro da organização e conceitos sobre satisfação e valor dos clientes mediante ao que a organização oferece. E também através de pesquisa bibliográfica, que teve o objetivo de formular um referencial teórico satisfatório para o entendimento dos fatores que dizem respeito ao estudo bem como sua posterior comparação com as questões levantadas por meio da prática.

O universo pesquisado se constitui no grupo de clientes da organização. Obteve-se uma amostra de 150 clientes escolhidos de forma não probabilística, constituindo-se em amostra de conveniência por adesão daqueles clientes que concordaram em responder ao questionário.

O instrumento foi constituído de um questionário, e a coleta se deu através da abordagem dos clientes de forma não probabilística dentro da organização, com o questionário onde os clientes preencheram o formulário de uma forma em que se propiciou o anonimato para que assim não se sentissem induzidos nas respostas e possibilitasse total espontaneidade.

O processo de tratamento dos dados se deu seguindo a linha de codificação das respostas, tabulação dos dados e cálculos estatísticos, utilizando a tabela Excel como ferramenta, produzindo assim materiais para uma possível análise.
A análise consiste em estabelecer fundamentalmente a ligação entre os dados obtidos no questionário, apresentados por meio de tabelas e gráficos, e os dados já conhecidos anteriormente através da teoria estudada.

\section{ANÁLISE DE DADOS}

Os resultados são apresentados com a demonstração de porcentagens referentes às escolhas dos clientes. Inicialmente o foco foi voltado a analisar o perfil dos clientes que assim se constitui na maioria sendo do sexo masculino com $63 \%$ dos clientes, porém, a presença feminina com $37 \%$ tem aumentado a medida que as mulheres se tornam cada vez mais independentes e a medida que os estabelecimentos se adaptam as suas necessidades. Constatado isto ainda deve-se focar no que a área masculina necessita por ser maioria na clientela, sem deixar de lado a ala feminina sendo um cliente em potencial.

A idade dos clientes apresentou a seguinte configuração:

Gráfico 1 - Idade dos clientes.

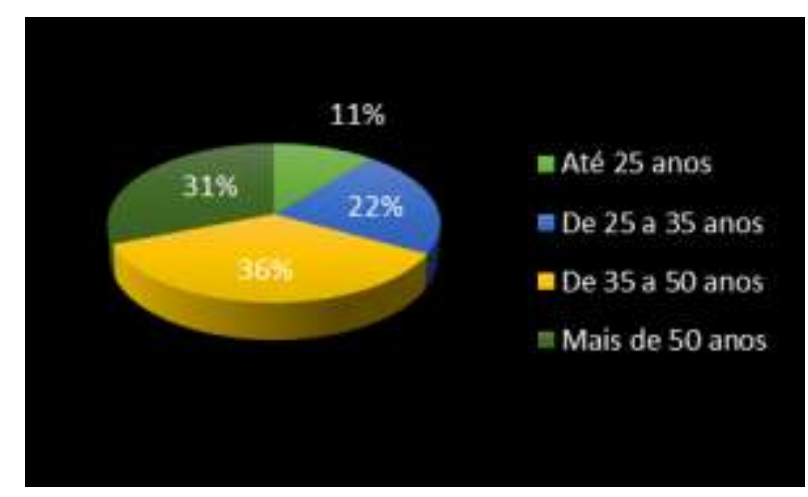

Fonte: Produzido pelos autores (2015). 
Analisando o Gráfico 1, é possível perceber que a maior parcela dos clientes possui mais de 35 anos. Coronel Barros por ser uma cidade agrícola e de pequena área, possui uma população de idade mais elevada, explicando em partes a alta porcentagem neste quesito, torna-se necessário então fazer um programa de vendas que atraia mais os jovens, os trazendo também até a conveniência e podendo talvez fidelizar os mesmos com produtos e promoções.

Gráfico 2 - Tempo em que os entrevistados são clientes do Posto e Conveniência Lara.

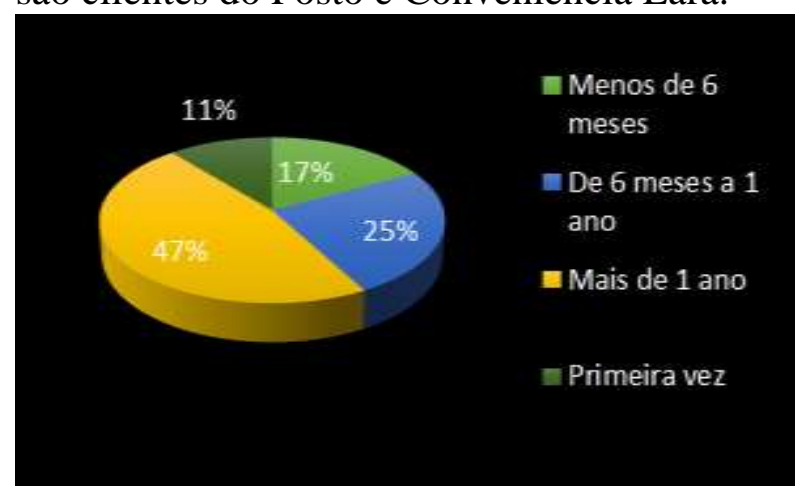

Fonte: Produzido pelos autores (2015).

O Gráfico 2 demonstra a fidelização já realizada na maioria dos consumidores que se mostram clientes há mais de um ano do Posto e Conveniência Lara totalizando $47 \%$ e também uma possibilidade grande de prospecção de novos clientes que hoje representam apenas $11 \%$.
Gráfico 3 - Aspectos influenciadores na escolha pelo Posto Lara.

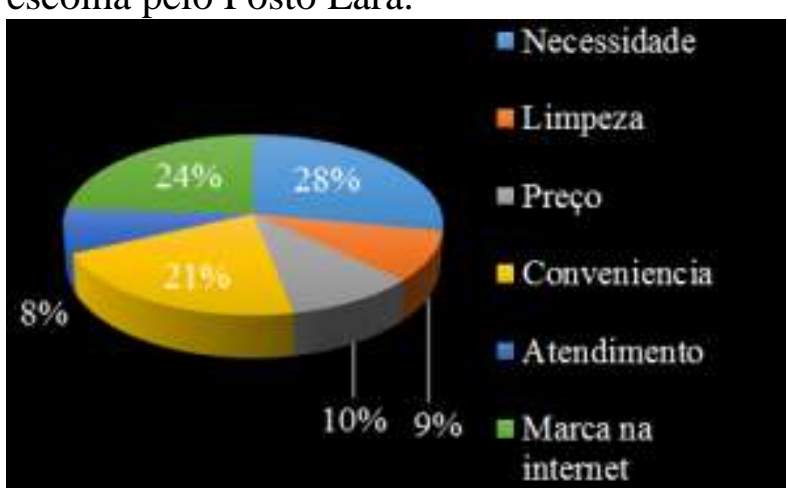

Fonte: Produzido pelos autores (2015).

Pode-se perceber no Gráfico 3 que o motivo da maioria dos clientes ao parar no Posto Lara é a necessidade com $28 \%$ da preferência, de acordo com Cobra (1984) o ser humano possui necessidades que muitas vezes são percebidas ou não pelas pessoas, é interessante aproveitar-se deste aspecto para um atendimento de qualidade fidelizando assim cada vez mais estes clientes e incentivando uma possível compra por impulso. Sendo também a força da marca na internet uma importante aliada na preferência dos clientes. Sem deixar de focar nos demais aspectos como limpeza, conveniência e preço que juntos somaram $40 \%$ da preferência dos clientes, e buscar melhorias no quesito atendimento que se mostra deficiente em uma análise inicial por parte dos clientes, por fim é necessária uma busca por novos atrativos que possam trazer ainda mais os clientes para as instalações da organização.

Em uma análise de o que os clientes buscam em uma loja de conveniência, os 
resultados apontam as alternativas descritas no Gráfico 4:

Gráfico 4 - Análise do que é procurado em uma conveniência.

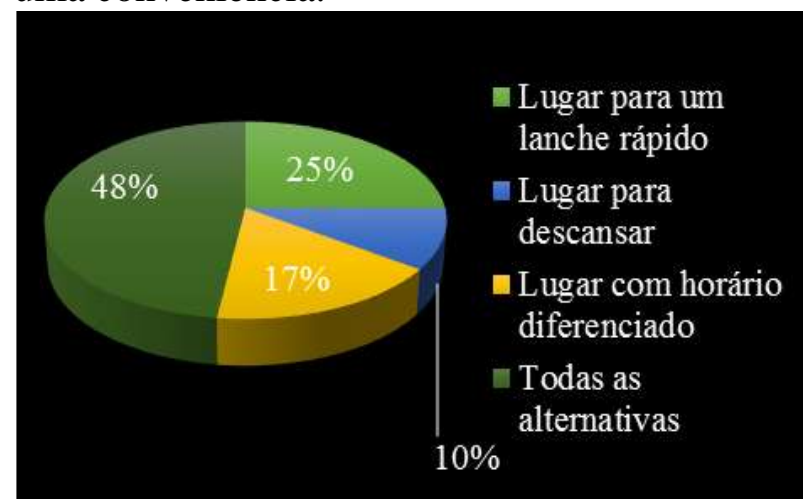

Fonte: Produzido pelos autores (2015).

Atualmente as pessoas necessitam de comodidade, agilidade e versatilidade, com suas vidas cada vez mais imediatas, e sem tempo, as conveniências acabam se tornando tanto um ponto de encontro, quanto um local para descanso com um horário diferenciado de atendimento, conforme demonstrado no Gráfico 4 com um destaque para a opção Lugar para um lanche rápido destacada com $25 \%$ da preferência dos clientes, e $17 \%$ para local com horário diferenciado. Segundo Ferreira (2008) conveniência em atividade comercial, seria uma organização responsável por providenciar mercadorias e serviços desejados pelos consumidores, possibilitando rapidez, facilidade e englobe como no caso dos postos de combustível, vários fatores de necessidade dos clientes em um modelo só, como um local para abastecer os veículos, com facilidade de estacionamento, segurança e que comercialize também produtos de sua necessidade diária. O que fica evidente com $48 \%$ dos votos em Todas as alternativas é que o que é procurado em uma conveniência é muito variável, porém ao mesmo tempo comum entre as pessoas, que apenas necessitam de um espaço para relaxar podendo fazer um lanche sem se preocupar com horário.

Analisando se a Conveniência Lara teve capacidade de suprir estas necessidades e expectativas dos clientes, foram obtidos os seguintes dados:

Gráfico 5 - Existência destas opções na Conveniência Lara.

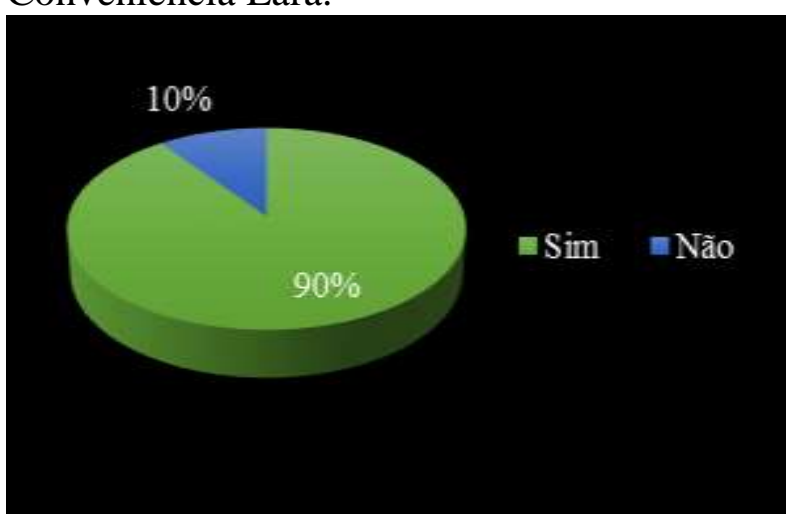

Fonte: Produzido pelos autores (2015).

Analisando o Gráfico 5 é possível perceber que a Conveniência Lara, foi eficaz na proposição destes aspectos, suprindo as necessidades dos clientes ao se dirigir ao estabelecimento de forma quase unânime com 90\% das opções como Sim, é necessário focar nos outros $10 \%$ que se deram devido a falta de opções de lanches nas gôndolas e estufas, fator que prejudica também a classificação da Conveniência Lara no quesito diversidade de produtos e acaba por frustrar clientes que 
buscam a conveniência com o intuito de um lanche rápido.

Transparecendo solução de todas as suas necessidades por parte da organização, os resultados foram os seguintes:

Gráfico 6 - Atendimento das necessidades dos clientes.

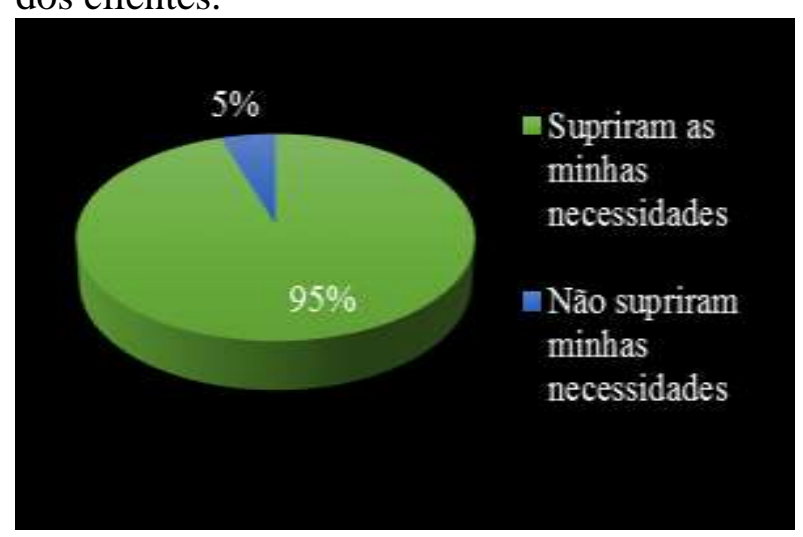

Fonte: Produzido pelos autores (2015).

A análise do Gráfico 6 nos identifica que o contentamento com os produtos e serviços do Posto e Conveniência Lara, no ponto de vista dos clientes foi de forma quase unânime satisfatória as suas necessidades com uma resposta positiva de $95 \%$ dos clientes. Segundo Las Casas (2006) para se chegar a um cliente satisfeito é necessário o conhecimento de suas necessidades, fazendoo perceber assim que houve um empenho por parte da organização na busca de tentar agrada-lo, e fazer um produto voltado para ele. É necessário verificar onde as instalações Lara não obtiveram êxito junto aos seus clientes e efetuar sua correção, para assim poder perceber de uma forma integral a necessidade dos seus clientes e satisfaze-los da melhor forma possível.

$\mathrm{Na}$ opinião dos clientes o que a implantação de uma loja de conveniência pode agregar em um posto de combustíveis, se deu da seguinte forma:

Gráfico 7 - Análise de quesitos agregados com a implantação de uma loja de conveniência.

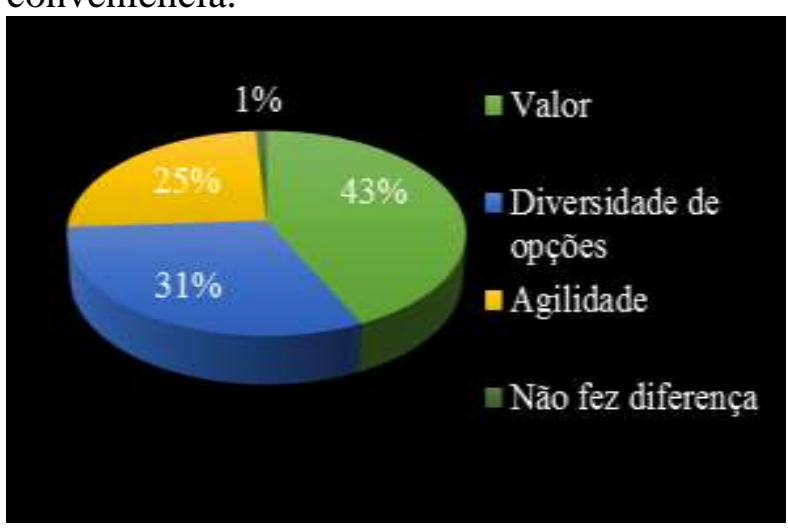

Fonte: Produzido pelos autores (2015).

A agregação de uma loja de conveniência a um posto de combustíveis traz inúmeras vantagens, não somente para a organização, como também para seus clientes, uma vez que o Gráfico 7 demonstra esta convergência de opiniões sendo que os quesitos valor, diversidade de opções e agilidade obtiveram percentuais parecidos chegando a $43 \%, \quad 31 \%$ e $25 \%$ respectivamente.

Segundo Gordon (2002), o vínculo de valor ocorre quando os clientes repetidamente obtêm o valor que procuram de seus fornecedores e têm todos os motivos para acreditar que continuarão a receber este valor durante um longo período. Seja ela da forma 
que for, esta criação de valor por parte do cliente acaba por deixa-lo fiel a organização. Demonstrando ainda mais esta percepção de valor agregado neste ramo, que de fato atualmente é mais fácil encontrar postos de combustíveis com conveniência do que se deparar com algum que abra mão deste diferencial.

Ao analisar a opinião dos clientes referente a importância de ações de marca na internet, obtiveram-se os seguintes dados:

Gráfico 8 - Valor percebido com ações de marca na internet.

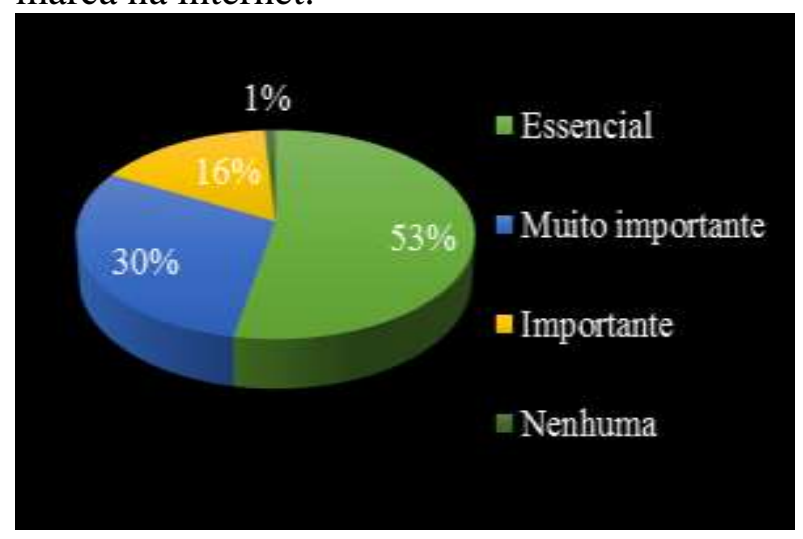

Fonte: Produzido pelos autores (2015).

A classificação de valor agregada as ações de marketing digital é demonstrada neste gráfico, com somadas as porcentagens entre essencial, muito importante e importante 99\% das opções, sendo que $86 \%$ representam somadas as alternativas essencial e muito importante. Possibilitando assim não somente a fidelização dos clientes da Conveniência Lara mas também do Posto Lara que ganham em valor com tais ações.
Segundo Torres (2010), marketing digital trata de um conjunto eficaz de ações que criam um contato de sua empresa com os seus consumidores, fazendo com que os mesmos conheçam seu negócio, confiem nele e tomem a decisão por realizar suas comprar a favor da organização.

Por fim, a análise de quais os motivos principais que os clientes consideram para uma possível volta ao Posto e Conveniência Lara se deu da seguinte forma:

Gráfico 8 - Aspectos influenciadores para o retorno ao Posto Lara.

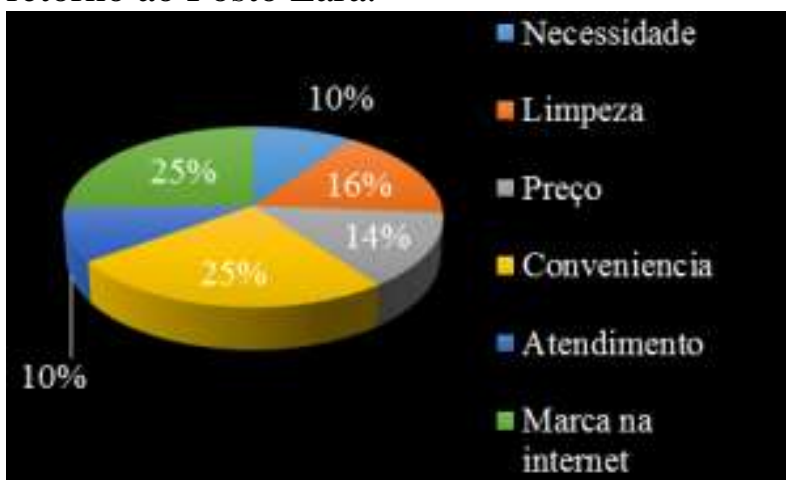

Fonte: Produzido pelos autores (2015).

Por fim, percebe-se no Gráfico 8 que os pontos fortes do Posto e Conveniência Lara são a marca na internet com $25 \%$ dos votos, e a conveniência também com $25 \%$ dos votos, juntamente com os preços e limpeza que juntos somam 30\%. Segundo Limeira (2003) a partir de uma prática eficaz das variáveis controláveis de marketing, é possível a criação de um valor para o cliente que resultara na satisfação de suas necessidades o tornando assim fiel a organização. É necessário analisar melhor o quesito 
atendimento, por ser de fundamental importância dentro de uma organização, e manter a qualidade nos quesitos que obtiveram boas classificações, sempre em busca de aperfeiçoamento na procura de novos clientes e permanência dos já existentes.

Sugestões e reclamações que surgiram de forma espontânea por parte dos entrevistados se resumem na seguinte configuração: Faltou maior diversidade de lanches; necessário um melhor atendimento com mais orientação sobre os produtos; melhorar a organização da loja de conveniência; maior agilidade no atendimento; preços muito elevados na Conveniência.

\section{CONSIDERAÇÕES FINAIS}

A realização deste artigo é de uma importância não somente acadêmica, mas também pessoal e profissional para o autor, uma vez que o mesmo está inserido dentro da organização estudada, e juntamente com os demais participantes deste estudo obteve um retorno muito positivo, em relação a conhecer melhor a organização e seus clientes, bem como proporcionar uma visão diferente do todo organizacional e suas falhas antes não percebidas.

Sendo possível identificar o perfil dos clientes da organização, bem como seus atributos de satisfação e percepção de valor em relação à implantação de uma loja de conveniência, bem como das ações realizadas pela organização na internet, unido ao estudo bibliográfico em livros, artigos e revistas, foi possível propor identificar fatores importantes na percepção dos clientes.

O tema satisfação é cada vez mais importante dentro das empresas, quando se fala em fidelidade dos clientes e lucratividade a longo prazo. Por meio dos dados obtidos no presente estudo e das proposições levantadas com o auxilio da teoria é possível formular um conjunto de ações com o objetivo de suprir as necessidades dos clientes, tornandoos cada vez mais satisfeitos com a organização e por consequência criar um vinculo de fidelidade e garantia de que existe um esforço por parte dos colaboradores e gestores da empresa para o alcance cada vez maior destes aspectos.

Por fim, há uma percepção de que é de extrema importância estar ciente de forma atualizada das opiniões e reclamações dos clientes dentro de uma organização, pois os mesmos são a maior fonte de informações disponível para possíveis tomadas de decisão dentro da empresa, uma vez que cada dia mais se ruma para uma diferenciação voltada apenas ao atendimento das necessidades dos clientes, e também previsão das mesmas resultando em um cliente satisfeito e fiel a organização por ter a certeza de que a mesma se esforça para mantê-lo. 


\section{REFERÊNCIAS}

CINTRA, Flávia Cristina. Marketing digital:

A era da tecnologia on-line. Revista

Investigação. Universidade de Franca, São

Paulo. 2010. Disponível em: <

http://publicacoes.unifran.br/index.php/investi gacao/article/view/147/104> Acesso em: 08 jun. 2016.

COBRA, Marcos. Marketing Básico: uma perspectiva brasileira. São Paulo: Atlas, 1985. Administração de marketing. São

Paulo: Atlas, 2002.

FERREIRA, Aurélio Buarque de Holanda.

Dicionário Aurélio. Paraná: Editora Positivo Ltda, 2008.

GIL, Antonio Carlos. Como elaborar

Projetos de Pesquisa. 4 ED. São Paulo:

Atlas, 2002.

GORDON, Ian. Marketing de

relacionamento: estratégias, técnicas e tecnologias para conquistar clientes e mantêlos para sempre. São Paulo: Futura, 2002.

LAS CASAS, Alexandre Luzzi. Marketing de Serviços. 4 ed. São Paulo: Atlas, 2006.

LEVY, Michael; WEITZ, Barton A.

Administração de varejo. São Paulo: Atlas, 2000.

LIMEIRA, Tânia Maria Vidigal. et al. Gestão de Marketing: Professores do Departamento de Mercadologia da FGV - EAEASP e Convidados. In: DIAS, Sergio Roberto (coord). Saraiva, 2003.

TORRES, Claudio. Guia prático de marketing na internet para pequenas empresas: Dicas para posicionar o seu negócio e conquistar novos clientes na Internet. São Paulo: Copyright, 2010. 